\title{
Emphasis on Complicated Diverticulitis
}

Maddalena Zippi ${ }^{{ }^{*}}$, Giampiero Traversa ${ }^{1}$, Wandong Hong ${ }^{2}$, Giuseppe Grassi ${ }^{1}$ and Ingrid Febbraro ${ }^{1}$

${ }^{1}$ Unit of Gastroenterology and Digestive Endoscopy, Sandro Pertini Hospital, Rome, Italy

${ }^{2}$ Department of Gastroenterology and Hepatology, First Affiliated Hospital of Wenzhou Medical University, Wenzhou City, Zhejiang, The People's Republic of China

Data emerging from the literature show how diverticulitis may turn out to become complicated in about $25 \%$ of cases (abscess, fistulization, bleeding, obstruction with or without stricture, peritonitis up to sepsis), of which approximately $15 \%$ need surgery [1]. Generally, no previous symptoms are related to the underlying diverticular disease [1].

A 57-year-old woman was admitted to our Unit for pneumaturia and fecaluriaassociated with fever $\left(38-39^{\circ} \mathrm{C}\right)$, appeared in the three days prior to the visit. An anamnestic history did not reveal pastdiagnosis of diverticular disease. Furthermore, there was no personal or family history of inflammatory bowel disease, no prior findings of colon cancer,except fora previoushysterectomyperformed for a benign disease. On admission,increased white blood cell count $\left(17,23 / \mathrm{mm}^{3}\right.$, neutrophils $87,8 \%$ ) and index of inflammation (CRP $5.3 \mathrm{mg} / \mathrm{dL}$ ) were present. On physical examination, the abdomen was poorly treatable

\section{Publication History:}

Received: December 23, 2016

Accepted: March 29, 2017

Published: March 31, 2017

\section{Keywords:}

Colovescical fistula (CVF), Diverticulitis, Fecaluria, Pneumaturia Surgery

In case of diverticulitis, the incidence of fistulas isabout $4-20 \%$ with a prevalence of thecolovesical ones (CVF) [2], more frequently occurring in males, as in females the uterus is located between thecolon and bladder.This finding is supported by the observationthat the majority of women with fistulas (colovesical or colovaginal) underwent a prior hysterectomy [3]. Recently, Miyaso et al. reported10 cases of CVFs, caused by sigmoid diverticulitis, showing how

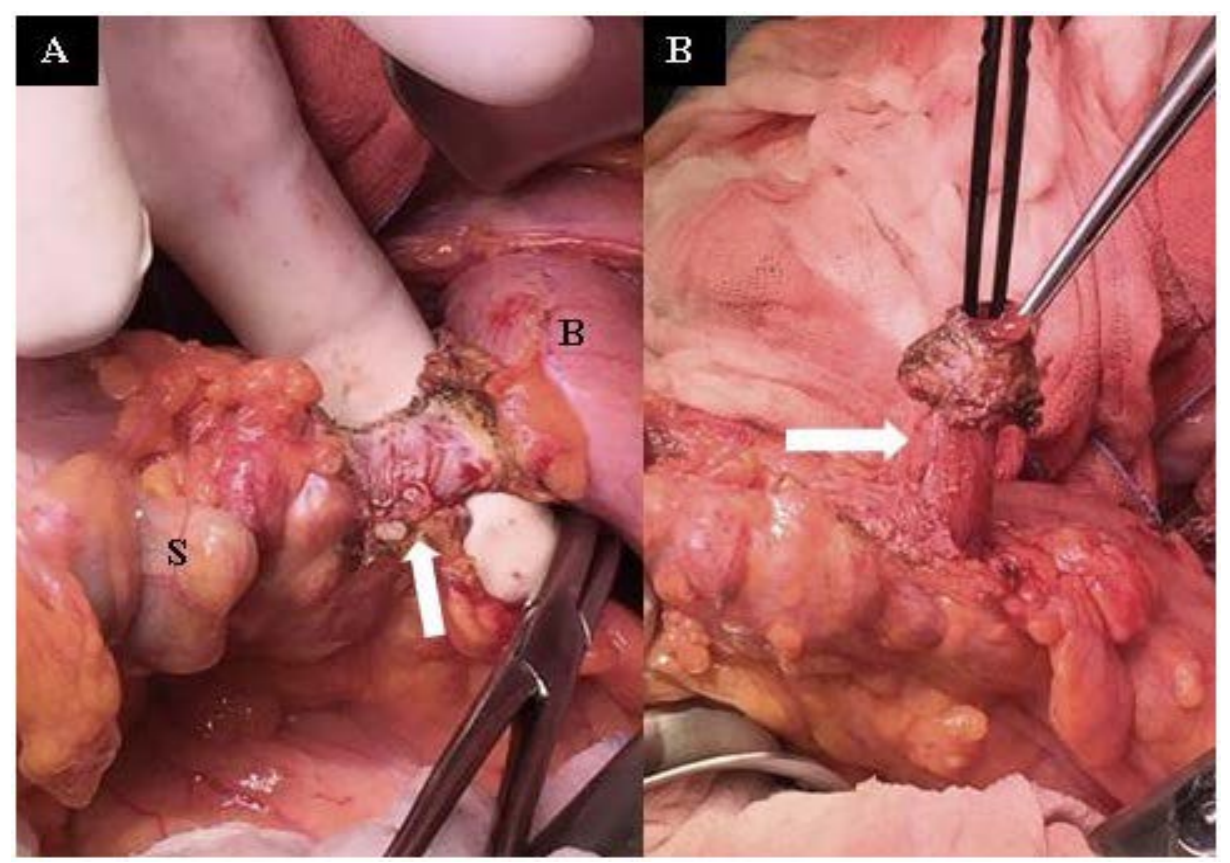

Figure 1: Surgical view:A) the sigmoid colon (S) and the bladder (B) were adhered to each other, and it was possible to identify the penetrating sigmoid diverticula into the bladder (white arrow); B) forceps showed the fistulazing diverticula opened in the bladder (white arrow).

with signs of mild peritoneal reaction. The patient underwent an abdominal computed tomography with contrast agent showing signs of sigmoid diverticulitis and gas in the bladder. A fistulography revealed a colovescical fistula. A one-step laparotomywas led in order to achieve a better visualization of the surgical field. At the beginning of the procedure, the sigmoid colon appeared strongly adherent to the bladder and the location of the fistula was observed (Figure 1). After adhesiolysis, a left hemicolectomy associated with repair of the bladder's wall defect were performed. Bowel rest, parenteral nutrition and intravenous broad-spectrum antibiotic therapy were started. The patient recovered well and was discharged 10 days after in good condition. fecaluria and pneumaturia were present in $40 \%$ and $30 \%$, respectively, as clinical presentation [4]. In conclusion, CVF due to sigmoid

"Corresponding Author: Dr. Maddalena Zippi, Unit of Gastronterology and Digestive Endoscopy, Sandro Pertini, Hospital, Via dei Monti Tiburtini 385, 00157 Rome, Italy, E-mail: maddyzip@yahoo.it

Citation: Zippi M, Traversa G, Hong W, Grassi G, Febbraro I (2017) Emphasis on Complicated Diverticulitis. Int J Gastroenterol Disord Ther 4: 126. doi: https:// doi.org/10.15344/2393-8498/2017/126

Copyright: @ 2017 Zippi et al. This is an open-access article distributed under the terms of the Creative Commons Attribution License, which permits unrestricted use, distribution, and reproduction in any medium, provided the original author and source are credited. 
Citation: Zippi M, Traversa G, Hong W, Grassi G, Febbraro I (2017) Emphasis on Complicated Diverticulitis. Int J Gastroenterol Disord Ther 4: 126. doi: https:// doi.org/10.15344/2393-8498/2017/126

Page 2 of 2

diverticulitis is a relatively rare disease and early surgical treatment is the best option.

\section{Competing Interests}

The author(s) declare that they have no competing interests.

\section{References}

1. Morris AM, Regenbogen SE, Hardiman KM, Hendren S (2014) Sigmoid diverticulitis: a systematic review. JAMA 311: $287-297$

2. Menenakos E, Hahnloser D, Nassiopoulos K, Chanson C, Sinclair V, et al. (2003) Laparoscopic surgery for fistulas that complicate diverticular disease. Langenbecks Arch Surg. 388: 189-193.

3. Floch CL. Diagnosis and management of acute diverticultis. J ClinGastroenterol 40: S136-S144.

4. Miyaso H, Iwakawa K, Hamada Y, Yasui N, Nishii G, et al. (2015) Ten Cases of Colovesical Fistula due to Sigmoid Diverticulitis. Hiroshima J Med Sci 64: 9-13. 